\title{
WAVE ENERGY CONVERSION SYSTEM USING ASYNCHRONOUS GENERATORS - A COMPARATIVE STUDY
}

\author{
Machado, I. R. ${ }^{(1)}$; Bozzi, F. A. ${ }^{(1)}$; Watanabe, E. $\mathrm{H}^{(1)}$; Garcia-Rosa, P.B. ${ }^{(2)}$; Martínez, M. ${ }^{(3)}$; Molina, M.G. ${ }^{(3)}$; \\ Mercado, P.E. ${ }^{(3)}$ \\ (1) Universidade Federal do Rio de \\ Janeiro - COPPE/UFRJ - Laboratório \\ de Eletrônica de Potência - ELEPOT \\ (2) Universidade Federal do Rio de \\ Janeiro - COPPE/UFRJ - Laboratório \\ de Tecnologia Submarina - LTS \\ (3) IEE - Instituto de Energía \\ Eléctrica Universidad Nacional \\ de San Juan - Argentina.
}

Caixa Postal: 68504, CEP: 21941-972

isaac@coe.ufrj.br, fabriciomtb@coe.ufrj.br, watanabe@coe.ufrj.br, paula@lts.coppe.ufrj.br

\begin{abstract}
This paper presents a comparative analysis between the double-feed induction generator (DFIG) and directly connected squirrel cage induction generator (SCIG) when they are used in a wave energy conversion system. Simulation results are presented to illustrate the operating ranges of the asynchronous generators and the generated power by the system. The simulations are developed and implemented in PSCAD / EMTDC.
\end{abstract}

Keywords - Wave energy conversion, asynchronous generator, power quality.

\section{INTRODUCTION}

The diversification of renewable energy sources to produce electricity represents an alternative to carbon emissions reduction and the growing energy demand. In this framework, the energy obtained from ocean waves is a promising resource and may become a viable solution to island or countries with coastal areas. Since the oil crisis of 1973, several countries have investigated and in many cases demonstrated the conversion of wave energy into a usable form of energy. Since then, many wave energy converters (WECs) with different working principles have been developed. Recent reviews indicate that there are more than 50 WECs at various stages of development [1].

The WECs are usually based on the following working principles [2]: (i) Oscillating Water Column (OWC): the wave action makes the water level in an air chamber oscillate. Then, the air in the chamber is compressed and expanded generating an air flow through a Wells turbine coupled to an electrical generator; (ii) Overtopping Devices: the water of the wave crest is introduced, by over spilling, into a reservoir where it is stored at a level higher than the average level of the sea. Then, the potential energy of the stored water is converted through low-head hydraulic turbines; (iii) Oscillating Bodies: the wave action results in the movement of floating bodies either connected to a hydraulic system and a turbine (or motor) coupled to an electric generator or connected directly to a linear generator.

In this work, we consider an oscillating-body system connected to a hydraulic subsystem as the one in the wave energy hyperbaric converter $[3,4]$. The hydraulic subsystem is composed mainly of hydraulic pumps, a hydropneumatic accumulator and a hyperbaric chamber. In this energy converter, the water flow obtained from the oscillating body motion is displaced to the accumulator, which has an internal piston separating water from gas and is connected to a hyperbaric chamber previously pressurized. The pressurized flow of water activates a Pelton turbine coupled to a synchronous generator, as illustrated by Figure 1 .

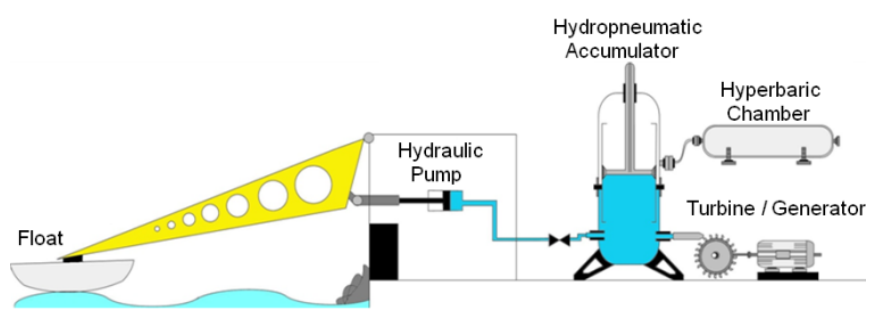

Fig. 1. Wave energy conversion system.

In this study, other topologies of generators are considered: the double-feed induction generator (DFIG) and the directly connected squirrel cage induction generator (SCIG). A comparative study between these asynchronous generators is presented to evaluate the performance of the system when variable speed operation is required. The power quality, operating ranges and efficiency are discussed.

\section{HYDRAULIC SYSTEM MODELING}

In order to analyze the application of different generators topologies in the WEC, we consider a steady-state model of the hydraulic system and the hydraulic turbine.

The hydraulic system considered in this paper is composed of hydraulic pumps, a hydropneumatic accumulator and a hyperbaric chamber, which is previously pressurized. Figure 2 presents a scheme of the hydropneumatic accumulator. The device consists of an internal piston that separates the water from the gas and moves freely. The hyperbaric chamber is coupled to the accumulator to increase the volume of gas, and therefore, the storage capacity.

The hydraulic model developed is based on the Bernoulli equation for incompressible fluids and Boyle-Mariotte law for isothermal systems [5]. Applying Bernoulli's equation to points 1 and 2 (Fig. 2)

$$
P_{1}+\frac{1}{2} \rho v_{1}^{2}+\rho g \Delta h^{\prime}=P_{2}+\frac{1}{2} \rho v_{2}^{2}+\rho g h_{2},
$$

where:

$P$ - Pressures in N/ $/ \mathrm{m}^{2}$;

$h$ - Levels of water in m;

$v$ - Water speed in $\mathrm{m} / \mathrm{s}$; 
$g$ - Gravity acceleration in $\mathrm{m} / \mathrm{s}^{2}$;

$A-$ Cross sections areas in $\mathrm{m}^{2}$;

$\rho$ - Watter specific mass in $\mathrm{kg} / \mathrm{m}^{3}$;

$\delta$ - Piston displacement in $\mathrm{m}$.

Considering that the water velocity in point 1 is approximately zero $\left(v_{1}=0\right)$, the output velocity $v_{2}$ is expressed by

$$
v_{2}(t)=\sqrt{2\left\{\left[g\left(\Delta h^{\prime}-h_{2}\right)+\left(\frac{P_{1}(t)-P_{2}}{\rho}\right)\right]\right\}},
$$

where $P_{1}$ is expressed by Boyle-Mariotte equation

and

$$
P_{1}(t)=P_{0}\left[\frac{\left(V_{t}-d A_{1}\right)}{V_{t}-(d+\delta(t)) A_{1}}\right],
$$

$$
\Delta h^{\prime}=h_{1}+\delta(t)
$$

where, $P_{0}$ and $V_{t}$ represent the initial pressure and the total volume, respectively.

The instantaneous position of the internal piston, $\delta(t)$, is obtained by the difference between the input and output water volumes given by

$$
A_{1} d \delta(t)=A_{0} d x-A_{2} v_{2} d t .
$$

and integrating (5)

$$
\delta(t)=\frac{A_{0}}{A_{1}} \int \frac{d x}{d t} d t-\frac{A_{2}}{A_{1}} \int v_{2} d t+\delta(0) .
$$

Multiplying the derivative term by $\mathrm{A}_{0}$, (6) becomes

$$
\delta(t)=\frac{1}{A_{1}} \int V z_{\text {in }} d t-\frac{A_{2}}{A_{1}} \int v_{2} d t+\delta(0),
$$

where $V z_{\text {in }}$ is the input parameter of the system. Note that in the hyperbaric converter, the body motion pumps water to the accumulator exclusively in the descendant motion of the body, as illustrated by Figure 3.

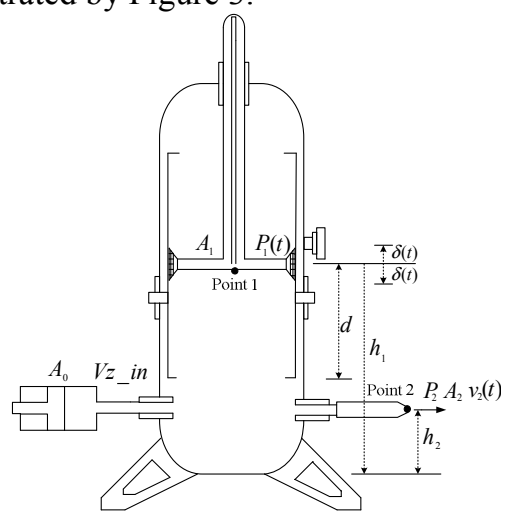

Fig. 2. Hydropneumatic Acummulator.

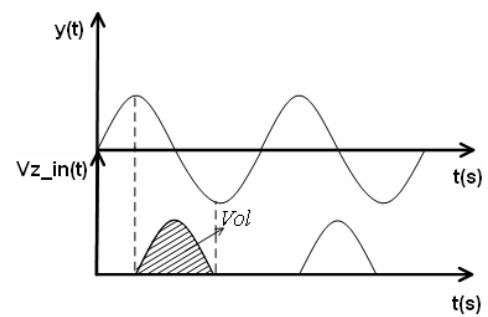

Fig. 3. Wave forms of the floating body position, $y(t)$, and input water flow, $V z_{i n}$.

\section{PELTON TURBINE MODELING}

For the steady-state operation of the turbine, we consider the water velocity of the incident jet $\left(v_{2}\right)$, the output area $\left(A_{2}\right)$, the angle $\theta$ and the radius of the turbine (R), as indicated by Figure 4, which presents a contour volume (CV) in the blade of the Pelton turbine. Thus, the torque is calculated as in [6],

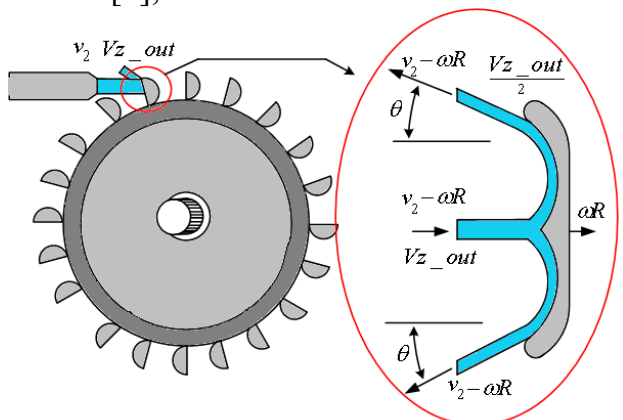

Fig. 4. Pelton turbine and modeling variables.

$\left(\begin{array}{c}\text { mechanical } \\ \text { torque }\end{array}\right)=\left(\begin{array}{c}\text { input angular moment } \\ \text { in C.V }\end{array}\right)+\left(\begin{array}{c}\text { output angular moment } \\ \text { in C.V }\end{array}\right)$

After replacing the variables,

$$
T_{\text {shaft }}=R\left(V_{2}-\omega R\right)(1+\cos \theta) \rho V_{2} A_{2},
$$

where $\omega$ is the speed of the turbine. The mechanical power is calculated as

$$
P_{\text {mec }}=\omega R\left(V_{2}-\omega R\right)(1+\cos \theta) \rho V_{2} A_{2} .
$$

Note that (10) represents a quadratic function, and then, the maximum efficiency conversion between hydraulic and mechanical power occurs at speed $\frac{\mathrm{V} 2}{2 \mathrm{R}}$, as it is illustrated by Figure 5 .

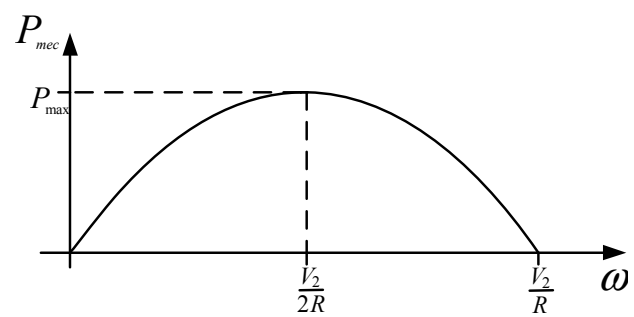

Fig. 5. Pelton turbine power curve.

\section{DFIG CONTROL}

Doubly fed induction machines with a wounded rotor have been used as variable speed electric generator especially in wind power generator systems. The stator winding is directly connected to the electrical grid and the rotor winding is connected to the electrical grid by a back-to-back converter. Figure 6 presents the DFIG topology.

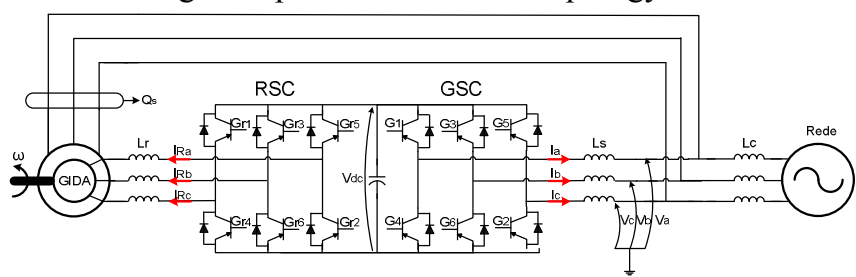

Fig. 6. DFIG topology. 
Control strategies for grid-side converter (GSC) and rotor-side converter (RSC) are presented in the next sections.

\section{A. Grid-side converter control}

Figure 7 shows the diagram of GSC control implemented in PSCAD / EMTDC. The measured signals are the phase voltages $\left(V_{a}, V_{b}\right.$ and $\left.V_{c}\right)$, line currents $\left(I_{a}, I_{b}\right.$ and $\left.I_{c}\right)$ and DC link voltage $(\mathrm{Vdc})$. The objective of the GSC is to keep the DC-link voltage constant regardless of the magnitude and direction of the rotor power. Two control loops based on instantaneous power theory [7] work in parallel, controlling active and reactive power independently. The active power is used to control the DC link voltage and reactive power control always in zero $\left(\mathrm{Q}_{\mathrm{ref}}=0\right)$. The current control based on vector control sine-modulated PWM (SPWM) is used [89].

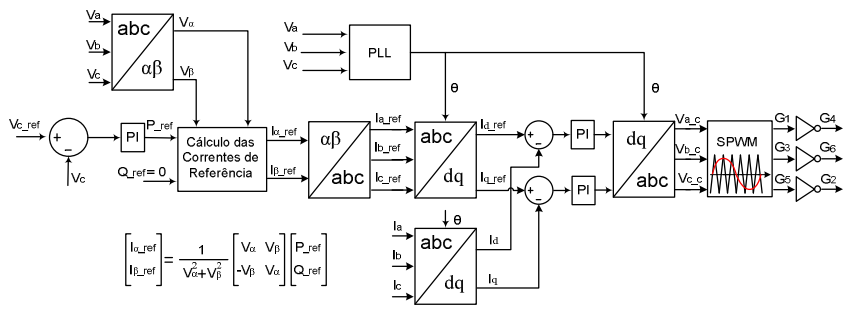

Fig. 7. Grid-side converter control strategy.

\section{B. Rotor-side converter control}

The vector control of the DFIG using a rotating reference frame fixed on the stator flux was implemented [10]. Figure 8 presents the vector diagram of the stator flux oriented control. The basic concept is to keep $i_{R d}$ current component aligned with the stator flux. So, DFIG can be controlled similarly to a DC machine, i.e., magnetization and electric torque controlled independently according to the variables $i_{r d}$ and $i_{r q}$, respectively.

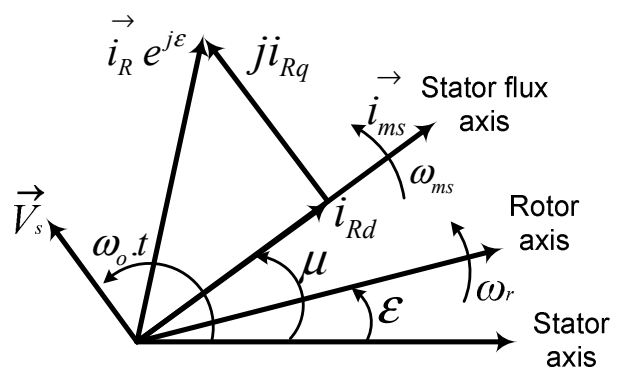

Fig. 8. Stator flux oriented control - vector diagram.

Figure 9 presents the control block of the RSC. Current vector control is implemented using the SPWM, based on comparison of voltage references with the triangular carrier wave. An important part of the stator flux oriented control is the estimation of the stator flux position. For location of this vector it is considered that the stator resistance is negligible, so the steady state voltage vector is nearly 90 degrees in advance of the stator flux (Figure 8).

\section{SIMULATION RESULTS}

The simulations were performed in order to compare two machines used in laboratory experiments. The DFIG and

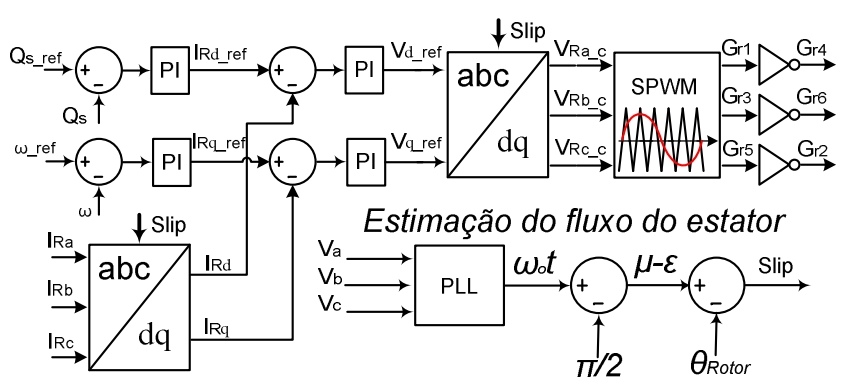

Fig. 9. Rotor-side converter control strategy.

SCIG have the same power rating and the parameters of the simulated machines are presented in Tables 1 and 2.

Table 1: Simulated DFIG Parameters.

\begin{tabular}{|c|c|}
\hline Parameter & Value \\
\hline Rated Power & $5.33 \mathrm{~kW}$ \\
\hline Rated Voltage & $220 \mathrm{~V}$ \\
\hline Poles Pairs & 1 \\
\hline Constant of Inertia & $0.5 \mathrm{~s}$ \\
\hline Stator Resistance & $0.0054 \mathrm{pu}$ \\
\hline Rotor Resistance & $0.00607 \mathrm{pu}$ \\
\hline Stator Leakage Inductance & $0.102 \mathrm{pu}$ \\
\hline Rotor Leakage Inductance & $0.11 \mathrm{pu}$ \\
\hline Magnetizing Inductance & $3.363 \mathrm{pu}$ \\
\hline
\end{tabular}

Table 2: Simulated SCIG Parameters.

\begin{tabular}{|c|c|}
\hline Parameter & Value \\
\hline Rated Power & $5.33 \mathrm{~kW}$ \\
\hline Rated Voltage & $220 \mathrm{~V}$ \\
\hline Poles Pairs & 1 \\
\hline Constant of Inertia & $0.5 \mathrm{~s}$ \\
\hline Stator Resistance & $0.0054 \mathrm{pu}$ \\
\hline Rotor Resistance & $0.00607 \mathrm{pu}$ \\
\hline Stator Leakage Inductance & $0.102 \mathrm{pu}$ \\
\hline Rotor Leakage Inductance & $0.11 \mathrm{pu}$ \\
\hline Magnetizing Inductance & $3.363 \mathrm{pu}$ \\
\hline
\end{tabular}

Variations in the operating range parameters of the hydraulic system storage (pressure, flow rate and volume) are simulated and the performance of the DFIG and SCIG are evaluated. Thus, three simulations cases have been implemented as presented in Table 3.

Table 3: Simulations Cases.

\begin{tabular}{|c|c|}
\hline \multicolumn{2}{|l|}{ Case 1} \\
\hline Average Input Water Flow & $2.15 \mathrm{l} / \mathrm{s}$ \\
\hline Internal Pressure & $2.7 \mathrm{e}+6 \mathrm{~N} / \mathrm{m}^{2}$ \\
\hline Chamber Internal Volume & $0.88 \mathrm{~m}^{3}$ \\
\hline \multicolumn{2}{|l|}{$\begin{array}{c}\text { Case } 2 \\
\end{array}$} \\
\hline Average Input Water Flow & $2.66 \mathrm{l} / \mathrm{s}$ \\
\hline Internal Pressure & $2.2 \mathrm{e}+6 \mathrm{~N} / \mathrm{m}^{2}$ \\
\hline Chamber Internal Volume & $0.88 \mathrm{~m}^{3}$ \\
\hline \multicolumn{2}{|l|}{$\begin{array}{rr}\text { Case } 3 \\
\end{array}$} \\
\hline Average Input Water Flow & $2.661 / \mathrm{s}$ \\
\hline Internal Pressure & $2.2 \mathrm{e}+6 \mathrm{~N} / \mathrm{m}^{2}$ \\
\hline Chamber Internal Volume & $0.2 \mathrm{~m}^{3}$ \\
\hline
\end{tabular}

Note that the product of water flow versus pressure (hydraulic power) is approximately constant in the cases 1,2 and 3. Case 3 is performed to evaluate the effect of lower hyperbaric chamber volume and pressure and water flow parameters were kept constant compared with the case 2 . 
- $\quad$ Case 1

In all simulations cases, the product of input water flow versus pressure of the hydraulic system is $5.8 \mathrm{~kW}$. In case 1 the hydraulic system pressure is higher than in cases 2 and 3. The output water flow area $A_{2}$ is adjusted so that water does not accumulate in the hydraulic system. Thus, the input volume of water in the hydraulic system every wave period $(\mathrm{T}=5 \mathrm{~s})$ must be fully released to the turbine. In the water flow graph $\left(V z_{\text {in }}\right.$, and $\left.V z_{\text {out }}\right)$ we can see that while the input water flow consists of periodic pulses (the water is pumped in the descent movement of the float body), the output water flow $V_{\text {zout }}$ is approximately constant $(2,171 / \mathrm{s})$. Therefore, the main function of the storage hydraulic system is observed: the filtering of the intermittent wave energy extracted. As will be observed in the simulation results, the level of water flow filtering is a direct function of the internal volume of the hyperbaric chamber. All simulations results are presented in pu, with bases of nominal generator ratings.

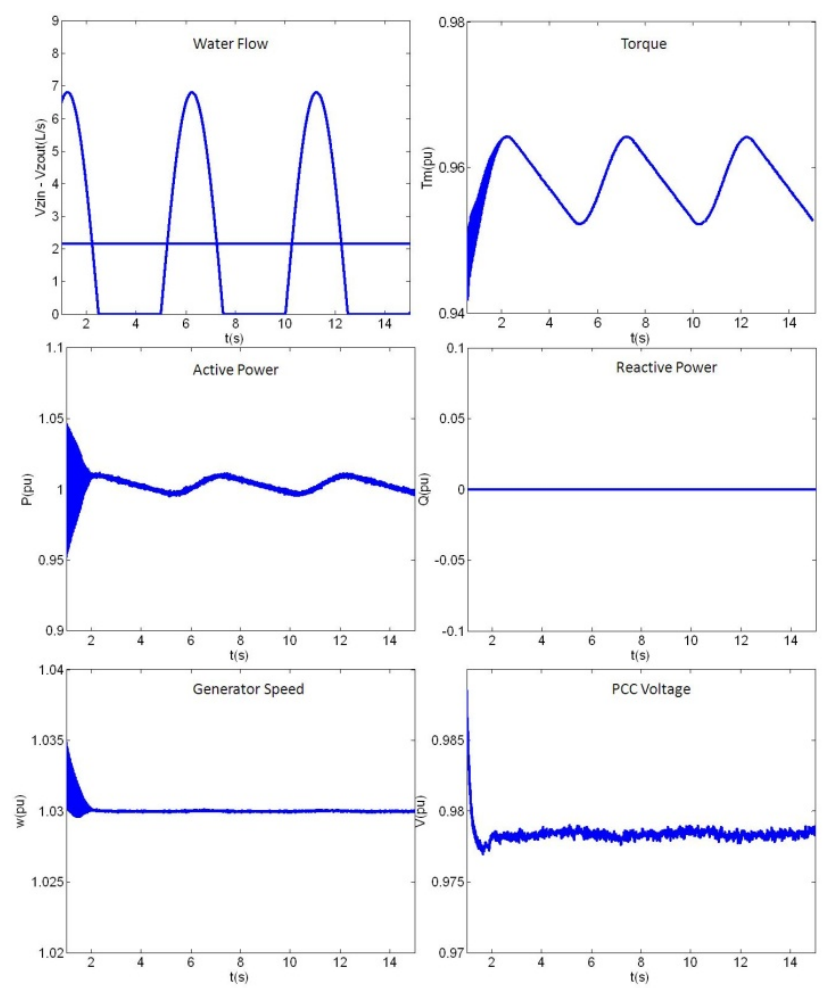

Fig. 10. Simulation results - DFIG - Case 1 .

In case 1 , the operating pressure is higher, hence the output water jet speed, $V_{2}$, is also higher. As shown in Figure 5, the optimal generator speed is directly related to $V_{2}$. Therefore, for an operating pressure of $2.7 \mathrm{MN} / \mathrm{m}^{2}$ the optimal generator speed is $1.03 \mathrm{pu}$.

Due to the large speed operation range of the DFIG, WECs plants equipped with this generator type have a greater flexibility in the hydraulic system operating pressure. This advantage is extremely important because the efficiency of primary conversion (wave energy to body motion) is directly related to the operating pressure of the system [11]. WECs plants equipped with SCIG are limited in speed operation range (operation above synchronous speed), then low pressure operation would not be feasible for this generator type. As in case 1, the SCIG speed is approximately $1.03 \mathrm{pu}$, the pressure presented in this
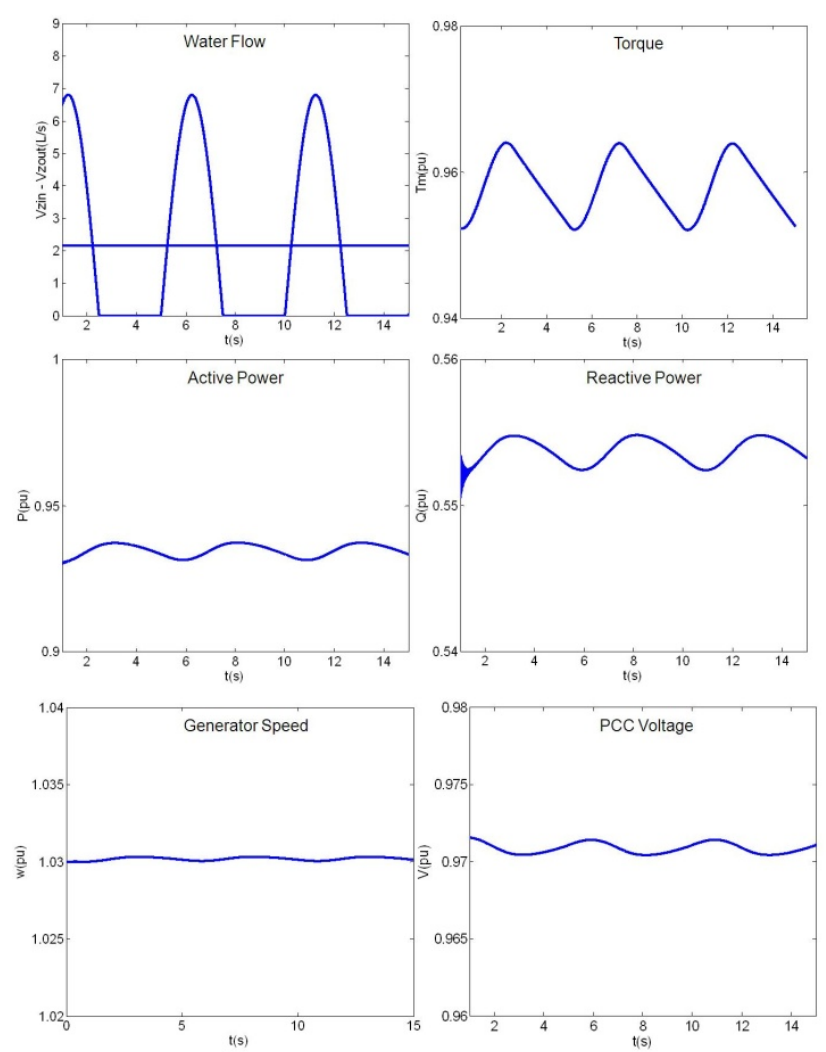

Fig. 11. Simulation results - SCIG - Case 1.

simulation case would be ideal for this generator type. Another important point to note is that higher operating pressures show a higher cost of the hydraulic storage system.

The generated power by DFIG (approximately $1 \mathrm{pu}$ ) was higher than the generated power by SCIG (approximately $0.88 \mathrm{pu}$ ), which indicates a greater efficiency for the DFIG topology. The SCIG topology requires reactive power drained from the grid, so the machine operates at a low power factor. As a consequence usually capacitors are connected at the generator terminals.

The voltages in the point of common connection (PCC) are set to approximately 0.975 pu for both generators, but for the SCIG case, the intermittent wave energy extracted has the greatest impact in PCC voltage fluctuations. As noted in case 3 , lower chamber volumes can cause low frequency voltage fluctuations. These fluctuations may result in several power quality problems, especially the Flicker effect.

\section{- $\quad$ Case 2}

In case 2 , the hydraulic system pressure was reduced to 2.2 $\mathrm{MN} / \mathrm{m}^{2}$. Consequently, the input flow was increased in order to maintain a constant hydraulic power in all cases. It is observed that the output water flow, $V z_{\text {out }}$, was increased to $2.641 / \mathrm{s}$. As the pressure was decreased, the output speed, $V_{2}$, must also suffer a decrease compared to case 1 and the optimal generator speed is $0.96 \mathrm{pu}$.

As the DFIG can operate at the optimal speed, the generated power is higher $(0.92 \mathrm{pu})$ than the generated power by the SCIG $(0.88 \mathrm{pu})$. The SCIG has limited operation at speeds greater than $1 \mathrm{pu}$ and therefore, it is not a good alternative for operating at low pressures. The operation at low pressures reduces the associated costs of the hydraulic 
storage system. However, this is not always desirable as the efficiency conversion between the wave energy and the body motion is also a function of the chamber pressure [11].

Besides, it can be observed that the PCC voltages present a similar behavior to case 1. The SCIG is more sensitive to the sea state and the intermittences and then, it exhibits larger voltage fluctuations than the DFIG.
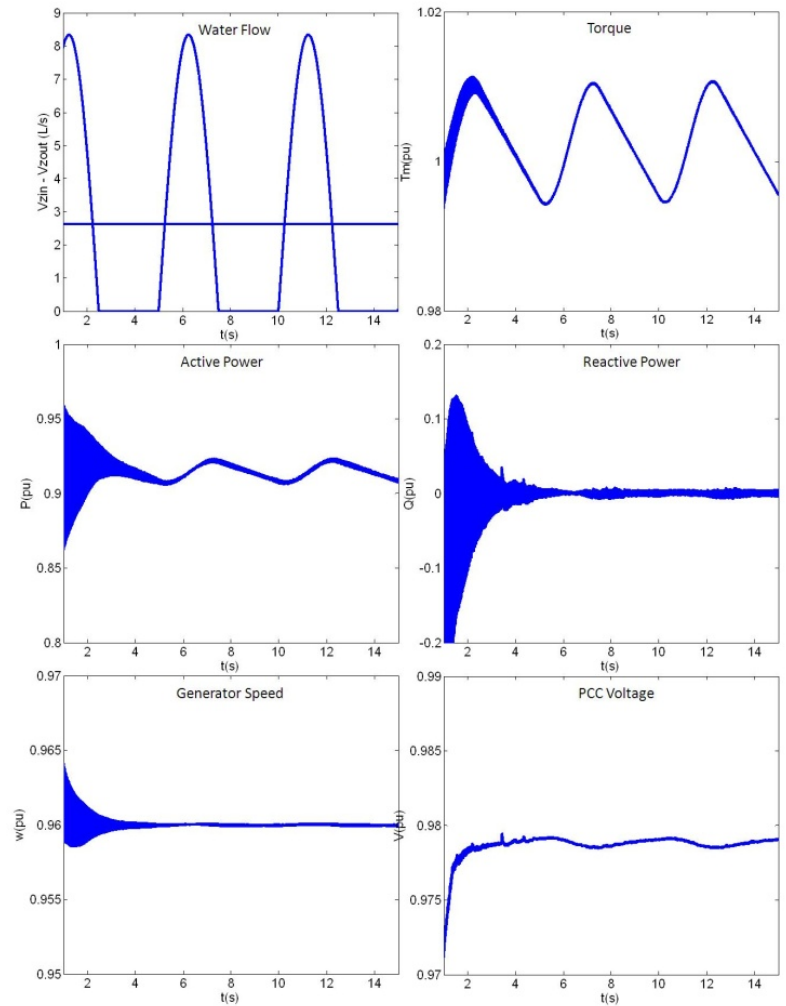

Fig. 12. Simulation results - DFIG - Case 2.

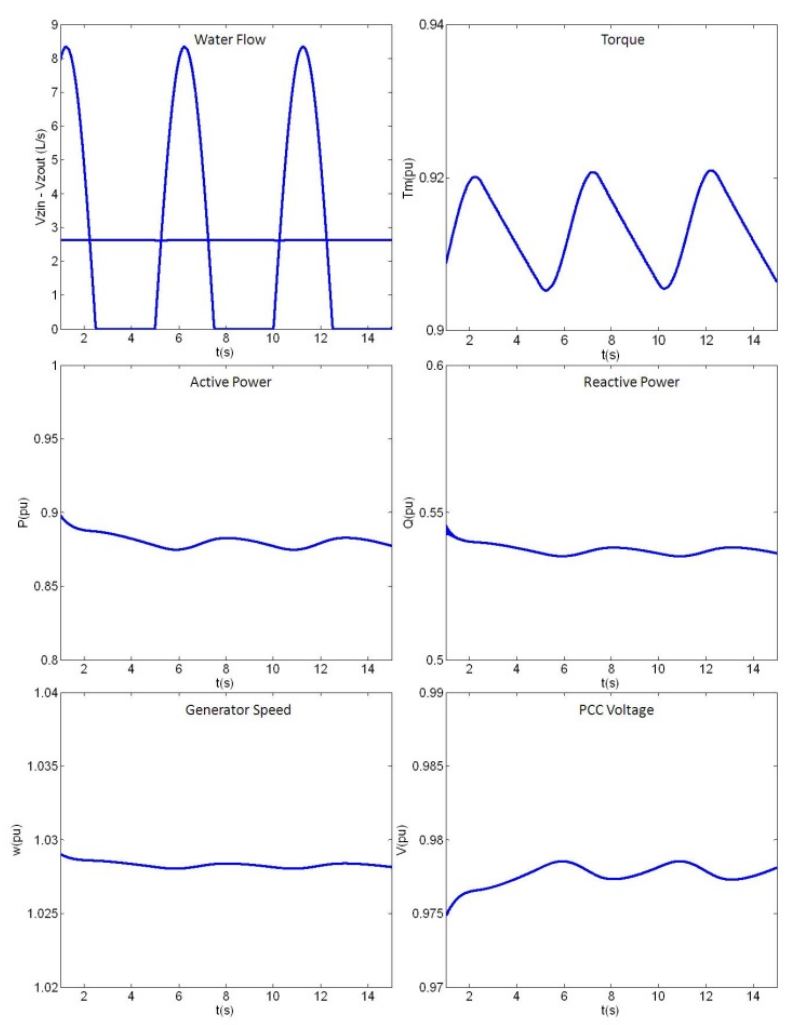

Fig. 13. Simulation results $-\mathrm{SCIG}-$ Case 2 .
- $\quad$ Case 3

The simulation parameters are the same of the previously simulation, except the volume of the chamber which is modified to $0.2 \mathrm{~m}^{3}$.
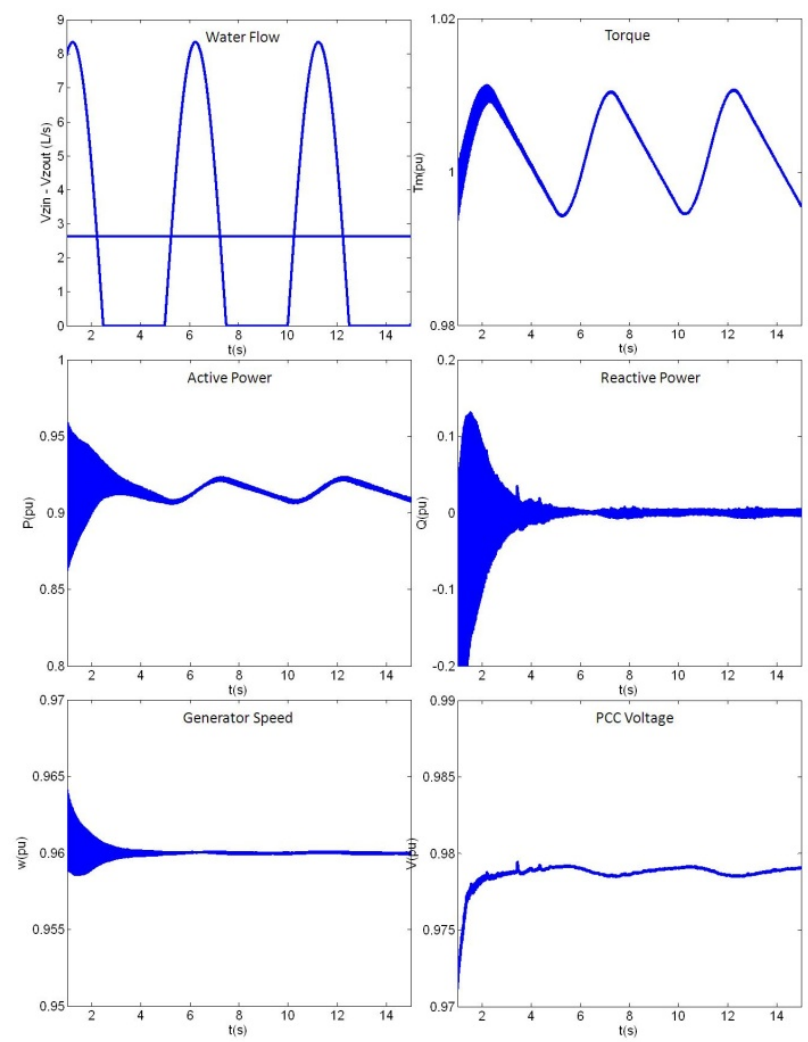

Fig. 14. Simulation results - DFIG - Case 3.
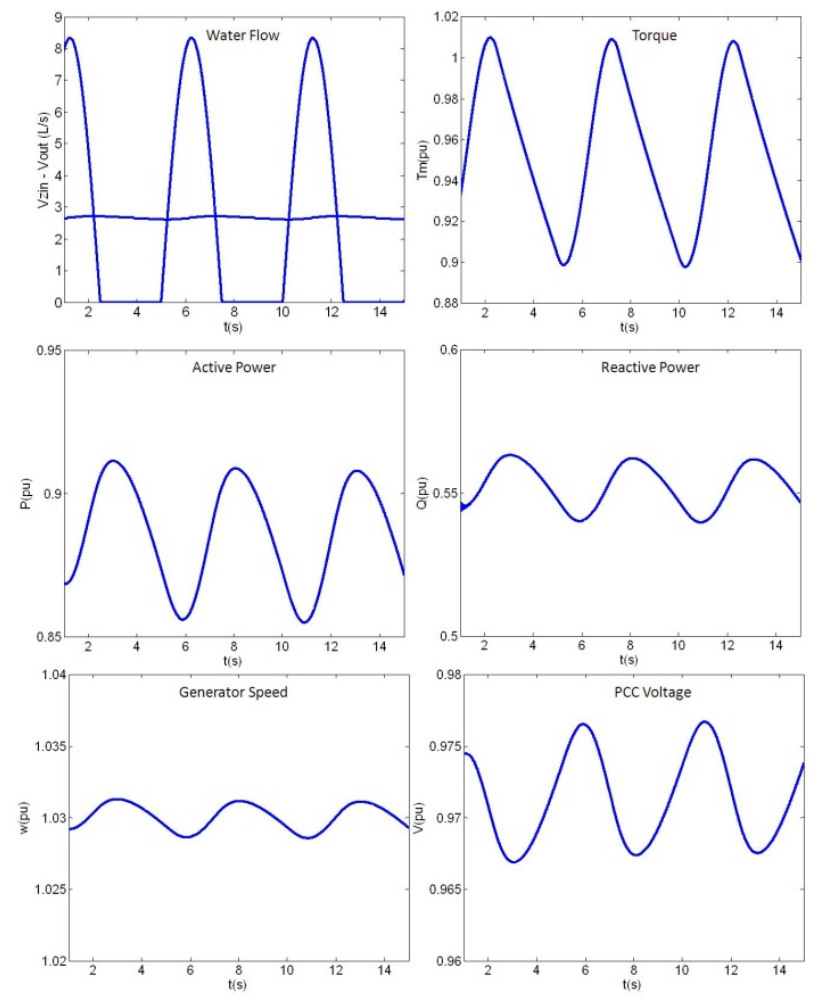

Fig. 15. Simulation results - SCIG - Case 3. 
The effect of decreasing the volume of the chamber is clearly observed in the graphics of flow $\left(V z_{i n}\right.$, and $\left.V z_{\text {out }}\right)$, Figs. 14 and 15. The fluctuations of the output water flow are more noticeable than cases 1 and 2 and it causes a torque fluctuation of approximately $0.1 \mathrm{pu}$ in both machines. The average output water flow is the same value of the case 2 $(2.64 \mathrm{~L} / \mathrm{s})$.

The generated power by the DFIG $(0.95 \mathrm{pu})$ is also higher than the SCIG $(0.88 \mathrm{pu})$, as the DFIG is operating at the optimal speed, $0.96 \mathrm{pu}$. Since the filtering level is less than the filtering presented in cases 1 and 2, the fluctuations of the generated power $(0.1 \mathrm{pu}$ and $0.05 \mathrm{pu}$, respectively for DFIG and SCIG) and the fluctuations of the PCC voltage are larger. The PCC voltage fluctuations are larger in the SCIG, as in this case, the reactive power presents the largest fluctuations.

\section{CONCLUSION}

This paper presented a brief comparison between DFIG and SCIG in a wave energy conversion system. The variable speed operation characteristic of the DFIG allows the maximum power point operation (Figure 5). Although SCIG is robust and has lower cost technology, it has limitations regarding the operation range and system performance.

According to the simulation results, the global efficiency of the system is low when the SCIG operates at low pressures, whereas the DFIG has flexibility to work at a wide range of operating pressures. The use of the gearbox could be an alternative to use SCIG topology in low hydraulic system pressures. On the other hand, gearbox usually requires more costs in maintenance.

The SCIG absorbs reactive power of the electrical grid, then the use of capacitors is usually required to improve the voltage level at PCC and to correct the power factor. For the DFIG case, this situation does not occur and it is still possible to apply the RSC and GSC controllers.

Besides, when the volume of the chamber is decreased, the DFIG is the generator that best suits this situation, as the torque fluctuations are damped in terms of PCC voltage fluctuations.

\section{ACKNOWLEDGEMENT}

This work received financial support from CNPq, CAPES, FAPERJ (Cientista do nosso estado) and CAPES / MinCyT. The authors acknowledge the technical support by LTS (Laboratório de Tecnologia Submarina) - COPPE / UFRJ.

\section{REFERENCES}

[1] A. Lewis, S. Estefen, J. Huckerby, W. Musial, T. Pontes, J. Torres Martinez, "Ocean Energy". in IPCC Special Report on Renewable Energy Sources and Climate Change Mitigation [O. Edenhofer, R. Pichs Madruga, Y. Sokona, K. Seyboth, P. Matschoss, S. Kadner, T. Zwickel, P. Eickemeier, G. Hansen, S. Schlömer, C. von Stechow (eds)], Cambridge University Press, Cambridge, United Kingdom and New York, NY, USA, 2011.

[2] A. F. O. Falcão, "Wave energy utilization: A review of the technologies," Renewable and Sustainable Energy Reviews, vol. 14, no. 3, pp. 899-918, 2010.

[3] S. F. Estefen, P. R. Costa, E. Ricarte, and M. M. Pinheiro, "Wave energy hyperbaric device for electricity production," in International Conference on Offshore Mechanics and Arctic Engineering, vol.OMAE-2007, San Diego (CA), 2007.

[4] P. B. Garcia-Rosa, I. R. Machado, J. P. V. S. da Cunha, F. Lizarralde, E. H. Watanabe, S. F. Estefen, "Modelagem da dinâmica de um conversor hiperbárico de energia das ondas em energia elétrica", in XVII Congresso brasileiro de Automática, Bonito/MS, 2010.

[5] D. Halliday, R. Resnick, J. Walker, Fundamentos de física, $7^{\mathrm{a}}$ edição. Capítulo 19 pp. 233-234. Livros técnicos e científicos editora S.A., 2006.

[6] Celso P. Livi, Fundamentos de Fenômenos de Transporte, Capítulo 5 pp. 83-93, Livros técnicos e Científicos Editora S.A, 2004.

[7] Hirofumi Akagi, Edson H. Watanabe, Mauricio Aredes, "Instantaneous Power Theory anda Applications to Power Conditioning", IEEE Press Editorial Board.

[8] Yamamoto, M., Motoyoshi, O., "Active and Reactive Control for Doubly-Fed Wound Rotor Induction Generator", IEEE Transactions on Power Eletronics, Vol. 6, nº 4 (Out), pp. 624-629, 1991.

[9] R. Pena, J.C.Clare, G. M. Asher, "Doubly fed induction generator uising back-to-back PWM converters and its application to variablespeed wind-energy generation", IEE Puoc.-Electr. Power Appl., Vol. 143, No 3, May 1996.

[10] Leonerd, W., Control of Electrical Drives, 3a ed., New York Springer, 2001.

[11] Garcia-Rosa, P.B., Cunha, J.P.V.S., Lizarralde, F., Estefen, S.F., Costa, P.R., "Efficiency optimization in a wave energy hyperbaric converter". In Proc. of the 2009 International Conference on Clean Electrical Power, Capri, Italy, pp. 68-75. 2009. 